\title{
Response of grass pea (Lathyrus sativus L.) photosynthetic apparatus to short-term intensive UV-A:red radiation
}

\author{
Krzysztof Tokarz ${ }^{1}$ - Barbara Piwowarczyk ${ }^{1}$ - Anna Wysocka ${ }^{1} \cdot$ Tomasz Wójtowicz $^{2}$ - Wojciech Makowski ${ }^{1}$. \\ Elżbieta Golemiec ${ }^{2}$
}

Received: 9 January 2019 / Revised: 22 August 2019 / Accepted: 26 August 2019 / Published online: 3 September 2019

(c) The Author(s) 2019

\begin{abstract}
Plants growing under natural conditions are constantly exposed to ultraviolet (UV), primarily UV-A, radiation. Grass pea (Lathyrus sativus L.) is a legume species resistant to harsh growing conditions, such as drought, salinity or periodic flooding. Due to the advantageous composition of seeds, it is used for consumption in such regions as South Asia or East Africa where high intensity of UV radiation occurs. Absorption of this spectral range causes changes in the photosynthetic apparatus of plants, including damage to the photosystem II (PSII) reaction centres. The aim of the work was to examine whether the use of the combination UV-A: red light as a source of radiation would enable quick acclimatization of the photosynthetic apparatus of grass pea to the negative effect of UV-A radiation. 14-day-old plants were exposed to UV-A:red radiation for $48 \mathrm{~h}$. The plants exposed to UV-A:red radiation showed enhanced effective efficiency of PSII and increased total electron carriers, which enabled more effective photosynthesis at higher values of radiation intensity in comparison with control plants, kept under white LED light. At the same time, there were no statistically significant differences in both the photosynthetic pigment contents and the level of lipid peroxidation. The obtained results indicate that the observed increase in the efficiency of $\mathrm{CO}_{2}$ carboxylation after short-term UV-A:red radiation has resulted from the efficient linear electron transport due to maintaining the effective oxygen evolving complex (OEC) and increased total electron carriers.
\end{abstract}

Keywords Chlorophyll $a$ fluorescence $\cdot$ Malondialdehyde $\cdot$ Photosystem II $\cdot$ Ultraviolet radiation

\section{Introduction}

Plants growing under natural conditions are constantly exposed to ultraviolet radiation. Considering the components of this radiation, UV-A (315-400 nm) has the lowest biological activity, but compared with UV-B (280-315 nm) and UV-C (100-280 nm) it penetrates into deeper tissues due to longer wavelengths (McKenzie et al. 2004). Regardless of the condition of the ozone layer, in the spectrum of

Communicated by P. Wojtaszek.

Krzysztof Tokarz

km.tokarz.ipbb@gmail.com; krzysztof.tokarz@urk.edu.pl

1 Unit of Botany and Plant Physiology, Institute of Plant Biology and Biotechnology, Faculty of Biotechnology and Horticulture, University of Agriculture in Krakow, Al. 29 Listopada 54, 31-425 Kraków, Poland

2 Department of Plant Breeding and Seed Science, Faculty of Agriculture and Economics, University of Agriculture in Krakow, ul. Łobzowska 24, 31-140 Kraków, Poland solar radiation reaching the Earth's surface UV radiation constitutes up to $6 \%$, in which almost $95 \%$ is UV-A radiation and only about 5\% is UV-B radiation (Moan 2001; Hollósy 2002).

The influence of UV-B radiation on plants is widely discussed in the literature, however, there are no similar studies regarding the response of plants to UV-A (Verdaguer et al. 2017). The UV radiation effect on plants leads to a number of changes in physiological processes, affecting especially the process of photosynthesis. One of the effects is photoinhibition of the photosystem II (PSII), comprehended as an imbalance between PSII photodamage caused by high irradiance, fluctuating light as well as short wavelength, and its subsequent repair ( $\mathrm{Li}$ et al. 2018). It is believed that: the main site of direct damage is the catalytic cluster $\mathrm{Mn}_{4} \mathrm{O}_{5} \mathrm{Ca}$; the resulting reactive oxygen species (ROS) additionally degrade the protein subunits D1 and D2 from the PSII reaction centre and damage the binding sites of QA and QB (Kale et al. 2017). On the other hand, there are reports about a positive effect of UV-A radiation on the photosynthetic 
apparatus, especially when UV-A radiation was used as a plant acclimation factor for UV-B under specific conditions (Štroch et al. 2015).

Although the UV-B:UV-A ratio undergoes quite significant changes both during the day and the year (due to unstable UV-B and constant UV-A transmission to the Earth's surface), there is a lot of information about the influence of these UV components on plants (Moan 2001; Verdaguer et al. 2017). Direct influence of ionizing radiation on plant cells is associated with: membrane lipid peroxidation (Urban et al. 2016), protein polymerization and enzyme deactivation (Urban et al. 2016); destruction of double bonds $\mathrm{C}=\mathrm{C}$ leading to changes in the structure of DNA and proteins (Urban et al. 2016 and literature therein), disorder of ion transport, depolarization of membranes and increase in their permeability (Wuytack et al. 2003). Moreover, UV radiation influences the photosynthesis process which is associated with (1) disturbances in the synthesis of chlorophyll pigments (degradation of alpha amino levulinic dehydrogenase ALAD) (Urban et al. 2016); (2) disorders in the synthesis of carotenoid pigments (MEP pathway) (Giuliano 2014) as well as (3) degradation of pigments related to radiationinduced senescence and/or radiation-induced programmed cell death (Kataria et al. 2014; Urban et al. 2016; Verdaguer et al. 2017). However, the influence of UV-A radiation in relation to the UV-A:PAR ratio is poorly understood (Barnes et al. 2013; Verdaguer et al. 2017).

Grass pea (Lathyrus sativus L.) is a legume species resistant to harsh growing conditions, such as drought, salinity or periodic flooding (Piwowarczyk et al. 2014, 2016, 2017). Due to the advantageous composition of seeds, high level (approx. 30\% of eed dry weight) of protein rich in exogenous amino acid-lysine (Grela et al. 2010), it is used for consumption in Central and South Asia or East Africa (Vaz Patto et al. 2006). In these regions (near the equator) the intensity of UV radiation is the highest (Moan 2001).

We hypothesized that red light, improving the light and/ or dark reactions of photosynthesis, would reduce the risk of ROS action on PSII RC under UV-A radiation. Therefore the aim of the work was to examine whether UV-A:red light radiation would enable quick acclimation of the photosynthetic apparatus of grass pea to the UV-A negative effect.

\section{Materials and methods}

\section{Plant material and experimental conditions}

The plant material comprised of the Polish grass pea cultivar 'Krab'. Seeds were sown in pots (12 $\mathrm{cm}$ in diameter) containing horticultural soil (sandy-loam) (Biovita, Tenczynek, Poland). The pots were placed in a grow room at a temperature of $23 \pm 2{ }^{\circ} \mathrm{C}$ under white LED lighting (intensity
$120 \mu \mathrm{mol}$ [quanta] $\mathrm{m}^{-2} \cdot \mathrm{s}^{-1}$, spectral composition Fig. 1a) and a 16-h photoperiod. The plants were watered every 2-3 days. 14-day-old seedlings were placed under UV-A:red light (ratio 10:90, intensity $110 \mu \mathrm{mol}$ [quanta] $\mathrm{m}^{-2} \cdot \mathrm{s}^{-1}$, spectral composition Fig. 1b) for 48 h. Control plants were kept under initial conditions. Twenty seedlings (five in each of four pots) were grown in each treatment.

\section{Measurements and assays}

The youngest, fully developed leaves (the 3rd node counting from the top of the plant) were used. Measurements were performed using 10 biological replicates (one replicate $=$ an individual leaf from an individual plant).

Photosynthetic pigment concentration was assayed spectrophotometrically (Double Beam spectrophotometer U-2900, Hitachi High-Technologies Corporation) using the method developed by Lichtenthaler (1987) and the equations as described by Wellburn (1994) [Chl $a=12.21 * A_{663}-2.81 * A 646 ; \mathrm{Chl} b=20.13 * A_{646}-5.03 * A_{663}$; $\left.\mathrm{Car}=\left(100 * A_{470}-3.27 * \mathrm{Chl} a-104 * \mathrm{Chl} b\right) / 198\right]$. The lipid peroxidation level, based on the malondialdehyde (MDA) content, was assessed according to Dhindsa et al. (1981). Chlorophyll $a$ fluorescence measurement was performed using a Handy-PEA (Hansatech, UK) fluorometer according to standard procedures. The leaves were dark-adapted for $25 \mathrm{~min}$. The fluorescence was induced by red light: $\lambda \max =650 \mathrm{~nm}$, $2000 \mu \mathrm{mol}$ [quanta] $\mathrm{m}^{-2} \cdot \mathrm{s}^{-1}$. Selected functional and
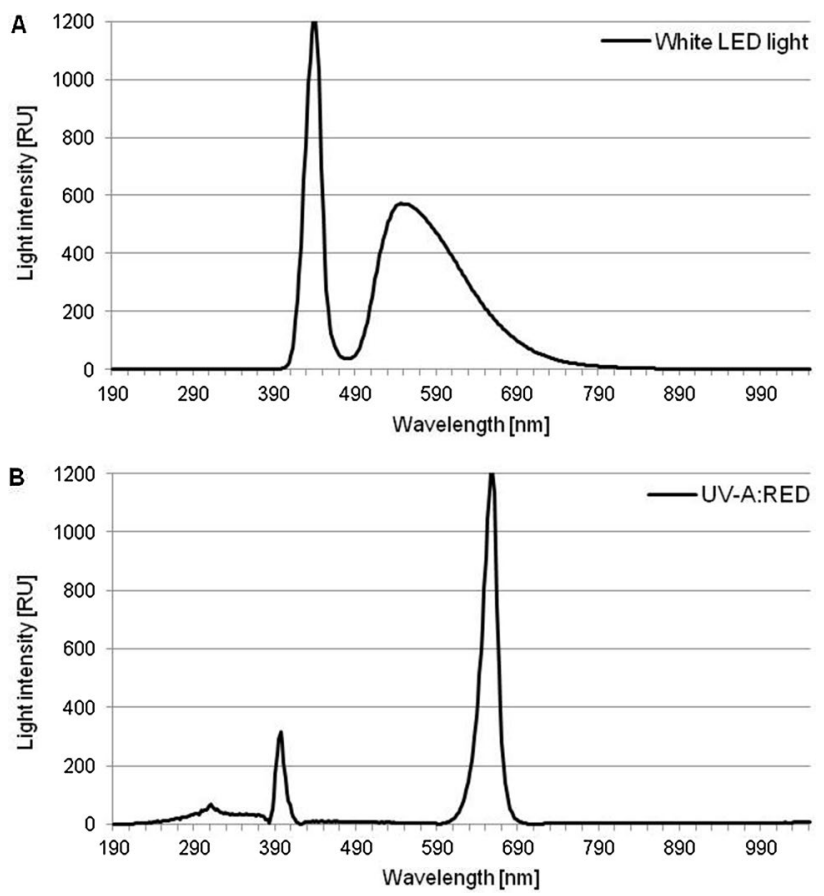

Fig. 1 Spectral composition of a white LED light and b UV-A: red light, $R U$ relative units 
structural photosynthetic parameters were extracted from the recorded curves using the fluorometer producer's software (PEA-Plus) and/or calculated according to Jiang et al. (2008) (Table 1-according to Piwowarczyk et al. 2018). Gas exchange measurements were carried out with a portable open gas-exchange system (LCpro-SD; ADC BioScientific Ltd UK) with a $6.24 \mathrm{~cm}^{2}$ cuvette with a mixed Red/Blue LED Light Source Head. Before recording the leaves were adapted for $2 \mathrm{~min}$ in the cuvette to allow photosynthesis to reach the steady state. Measurements were done under $\mathrm{CO}_{2}$ saturated conditions $\left(650 \mu \mathrm{mol} \cdot \mathrm{mol}^{-1}\right) ; 300 \mu \mathrm{mol} \cdot \mathrm{s}^{-1}$ of air flow, $50-55 \%$ relative humidity within the cuvette, leaf temperature of $25^{\circ} \mathrm{C}$ and under the $130 \mu \mathrm{mol}$ [quanta] $\mathrm{m}^{-2} \cdot \mathrm{s}^{-1}$ red light intensity. Photosynthetic light response curves were done on the same

Table 1 Abbreviations and descriptions of extracted and calculated photosynthetic parameters (Jiang et al. 2008; Kalaji et al. 2011; Piwowarczyk et al. 2018)

\begin{tabular}{lc}
\hline Extracted parameters & \\
\hline$F_{0}$ & Minimum fluorescence, when all \\
& PSII reaction centers (RCs) are \\
& open \\
& Maximum fluorescence, when all \\
& PSII reaction centers are closed \\
$F_{\mathrm{M}}$ & Fluorescence intensities at 50,100, \\
$F_{50 \mu \mathrm{s}}, F_{100 \mu \mathrm{s}}, F_{300 \mu \mathrm{s}}, F_{2 \mathrm{~ms}}, F_{30 \mathrm{~ms}}$ & $300 \mu \mathrm{s}, 2,30 \mathrm{~ms}$, respectively \\
Area & Total complementary area between \\
& fluorescence induction curve and \\
& $F=F_{M}$
\end{tabular}

Calculated parameters

\begin{tabular}{ll}
$F_{\mathrm{V}}$ & Variable fluorescence $F_{\mathrm{V}}=F_{\mathrm{M}}-F_{0}$ \\
$F_{\mathrm{V}} / F_{\mathrm{M}}$ & Maximum quantum yield of PSII \\
$F_{\mathrm{V}} / F_{0}$ & $\begin{array}{l}\text { Activity of the water-splitting complex on the donor } \\
\text { side of the PSII }\end{array}$ \\
\hline
\end{tabular}

OJIP parameters

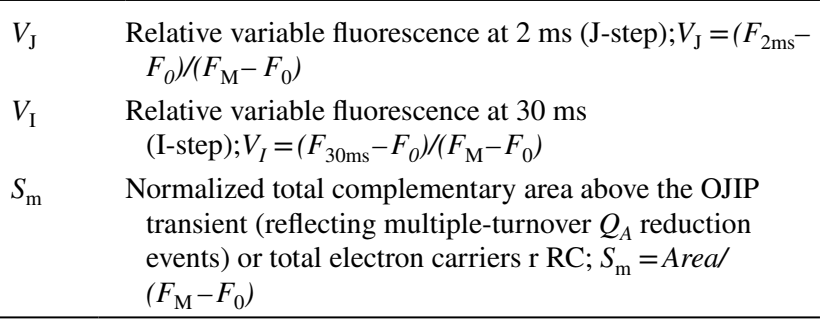

Yields or flux ratios

\footnotetext{
$\varphi_{\mathrm{Po}} \quad$ Maximum quantum yield of primary photochemistry at $t=0$; $\varphi_{P_{o}}=1-F_{0} / F_{\mathrm{M}}=F \mathrm{v} / F_{\mathrm{M}}$

$\varphi_{\mathrm{Eo}} \quad$ Quantum yield for electron transport at $t=0 ; \varphi_{E o}=\left(F \mathrm{~V} / F_{\mathrm{M}}\right)$ $\left(1-V_{\mathrm{J}}\right)$

$\psi_{\text {Eo }} \quad$ Probability (at time 0 ) that trapped exciton moves an electron into the electron transport chain beyond; $\psi_{E O}=1-V_{\mathrm{J}}$

$\rho_{\mathrm{Ro}} \quad$ Efficiency with which a trapped exciton can move an electron into the electron transport chain from $Q_{A}^{-}$to the PSI and electron acceptors; $=\psi_{E o} \delta_{R o}=\left(1-V_{\mathrm{J}}\right)\left(1-V_{\mathrm{I}}\right) /\left(1-V_{\mathrm{J}}\right)$
}

Table 1 (continued)

Yields or flux ratios

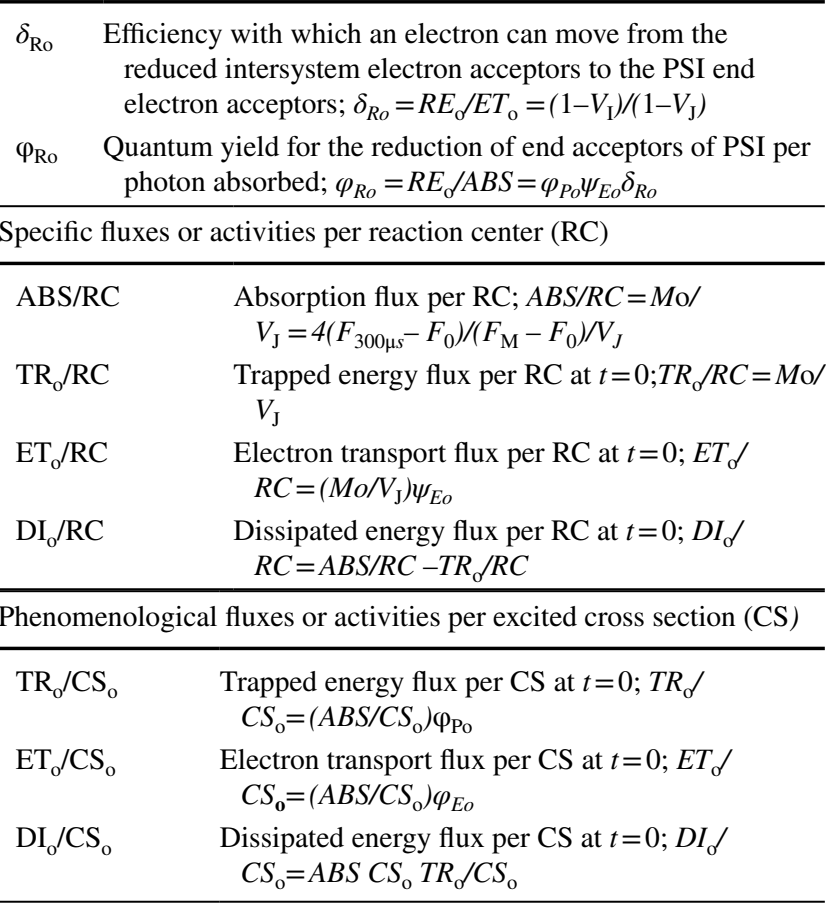

plants used for net photosynthesis for a stepwise reduction of PAR ranging from 1500 to $0 \mu \mathrm{mol}$ (quanta) $\mathrm{m}^{-2} \cdot \mathrm{s}^{-1}$ (in $100,50,20,0,100,300,500,1000,1500,300$ and $100 \mu \mathrm{mol}$ (quanta) $\mathrm{m}^{-2} \cdot \mathrm{s}^{-1}$ steps). The leaves were adapted to each of the light intensities for 5, 3, 2, 5, 5, 5, 5, 5, 5, 5 and $5 \mathrm{~min}$, respectively before data point recording. Air flow, relative humidity and $\mathrm{CO}_{2}$ concentration inside the cuvette were the same as described in the case of gas exchange measurement.

\section{Statistical analyses}

The results were subjected to statistical analyses using Statistica 12.0 (StatSoft Inc., Tulsa, OK, USA). The significant differences between the means of each treatment were determined using Duncan's test at $p<0.05$.

\section{Results and discussion}

The effect of UV-A radiation on the photosynthetic apparatus in a short period of time consisted in a rapid decrease in the chlorophyll pigment content. Salama et al. (2011) observed in the leaves of plants treated with UV-A + PAR radiation a decrease in the level of chlorophyll pigments ranging from $34 \%$ (Rumex vesicarius) to even $99 \%$ (Plantago major). Also the level of carotenoid pigments, whose function in the photosynthetic apparatus is connected on the one hand with supplying additional excitation energy to the reaction 
centre of the photosystem II (RC PSII), and on the other with the protection of PSII against photoinhibition and photooxidation by dissipating the excess absorbed light energy in the xanthophyll cycle, undergoes significant changes as a result of UV-A radiation. In the studies of Salama et al. (2011), UV-A radiation caused a statistically significant decrease in the carotenoid pigment content in most of the studied species. Our results revealed that UV-A radiation had no effect on chlorophyll $a$, chlorophyll $b$ and total chlorophyll as well as carotenoid contents in grass pea shoots (Fig. 2a). It seems that in grass pea plants chlorophyll and carotenoids synthesis pathways were not disturbed by UV-A radiation.

Alterations in the pigment content could also be associated with chloroplast damage. Besides direct destruction of plasmatic membranes by high energy UV radiation, plastid membranes might be damaged as a result of reactive oxygen species (ROS) activity (Urban et al. 2016). The source of ROS can include PSII malfunction as well as impairment of antioxidant enzymes (Urban et al. 2016). ROS cause changes in membrane lipid composition (increased level of unsaturated vs. saturated fatty acids) as well as potassium leakage and lipid peroxidation (Singh et al. 2010; Tokarz et al. 2018). In the case of grass pea, UV radiation had no significant effect on the MDA content (Fig. 2b), indicating lack of changes in the level of lipid peroxidation. Lack of changes in lipid peroxidation in leaves under stress conditions results in sufficient antioxidant system efficiency or efficient linear electron transport between PSII and PSI, or the conjunction of these two mechanisms (Piwowarczyk et al. 2018; Tokarz et al. 2018).

Moreover, the direct impact of UV on the photosynthetic apparatus is related to the damage to the oxygen-evolving complex (OEC), degradation of D1 and D2 proteins of PSII, degradation of the plastoquinone pool (PQ) as well as cytochrome $b_{6 \mathrm{f}}$ (Kataria et al. 2014; Urban et al. 2016; Verdaguer et al. 2017), which leads to disturbances in electron transport between PSII and PSI (Tyystjarvi and Vass 2004). In isolated spinach chloroplasts, UV-A radiation caused damage to PSII arising from disturbed electron transport on both the donor (OEC) and acceptor (PQ) sides (Tyystjarvi and Vass 2004). Damage to OEC, which is sensitive to high PAR intensities and UV-A radiation, leads to degradation of RC PSII from the electron 'donor side' (Zsiros et al. 2006). This process is caused by direct oxidation of $\mathrm{P} 680+$ or indirect inactivation of PSII RC by ROS formed on the donor side as a result of OEC degradation by UV-A radiation (Tyystjärvi 2008; Turcsányi and Vass 2000). Disturbances on the acceptor side of PSII are associated with degradation of PQ by UV radiation (Vass et al. 2005), which results in the permanently reduced state of the QA electron acceptor of PSII leading to photoinhibition of PSII RC (Tyystjärvi 2008). Measurement of chlorophyll $a$ fluorescence of grass pea leaves subjected to $48 \mathrm{~h}$ of UV-A:red light revealed that the donor side of PSII- OEC remained unchanged $\left(\mathrm{Fv} / \mathrm{Fo}_{\mathrm{O}}\right)$ (Fig. 2c). Furthermore, the electron flux beyond PSII RC $\left(\varphi_{\mathrm{Eo}}\right.$ and $\left.\psi_{\mathrm{Eo}}\right)$ and the electron transport flux $\left(\mathrm{ET}_{0}\right)$ per reaction center and per cross section of thylakoid increased significantly in leaves of stressed plants (Fig. 2c). Moreover, in grass pea plants exposed to UV-A:red radiation higher efficiency of RC was associated with a significant increase in total electron carriers per RC (Sm) (Fig. 2c). On the other hand, the dissipated energy flux $\left(\mathrm{DI}_{0}\right)$ per RC decreased (Fig. 2c). Similar changes in the photosynthetic apparatus efficiency were found in grass pea genotypes under drought stress conditions (Silvestre et al. 2014). We hypothesize that more efficient linear electron transport associated with the stable state of the donor side of PSII RC makes it possible to avoid the direct and/or indirect impact of UV-A radiation.

Most of the reports on the harmful effects of UV radiation on the photosynthetic apparatus concerned isolated chloroplasts or thylakoids. The research conducted on intact leaves indicated significantly higher resistance of the photosynthetic apparatus. Studies conducted on lettuce and Arabidopsis that were pre-illuminated with red light followed by UV-A revealed that pre-illumination with red light had a protective effect on the photosynthetic apparatus. Nevertheless, a significant decrease in net photosynthesis was observed (Kreslavski et al. 2013, 2016). Moreover, other authors observed a slight increase in the photosynthesis rate as a result of enhanced stomatal conductance and/or a reduction in the functional size of PSII (Joshi et al. 2007; Stroch et al. 2015; Verdaguer et al. 2017). Furthermore, plants exposed to shortwave radiation, but in the PAR range (Purple and Blue), were characterized by higher Rubisco activity and higher transcriptional levels of 10 genes of the key Calvin-Benson Cycle enzymes, which in turn did not result in higher rates of photosynthesis due to inactivation of PSII caused by that radiation (Wang et al. 2009).

In our studies, plants exposed to $48 \mathrm{~h}$ of UV-A:red light showed an increased rate of photosynthesis without changes in stomatal conductance and rate of transpiration (Table 2). Furthermore, the increasing rate of photosynthesis was pronounced at higher light intensities (Fig. 2d).

In summary, acclimatization of the photosynthetic apparatus of grass pea to UV-A stress conditions results from efficient linear electron transport due to maintaining the effective OEC complex $\left(F \mathrm{v} / F_{\mathrm{O}}\right.$ value $)$ and increased total electron carriers and/or effective $\mathrm{CO}_{2}$ carboxylation. 
Fig. 2 a Photosynthetic pigment content, $\mathbf{b}$ lipid peroxidation level expressed as the malondialdehyde (MDA) content, c extracted and calculated chlorophyll $a$ fluorescence parameters, $\mathbf{d ~ C O} \mathrm{CO}_{2}$ assimilation efficiency of photosynthesis of grass pea seedlings after $48 \mathrm{~h}$ of UV-A:red radiation treatment, $\mathbf{a}-\mathbf{b}$ error bars-standard deviations, $\mathbf{d}$ numbers are given as a percentage of the control (=100\%), abbreviations-see Table 1, *significant difference between treatments according to Duncan's test at $p<0.05$
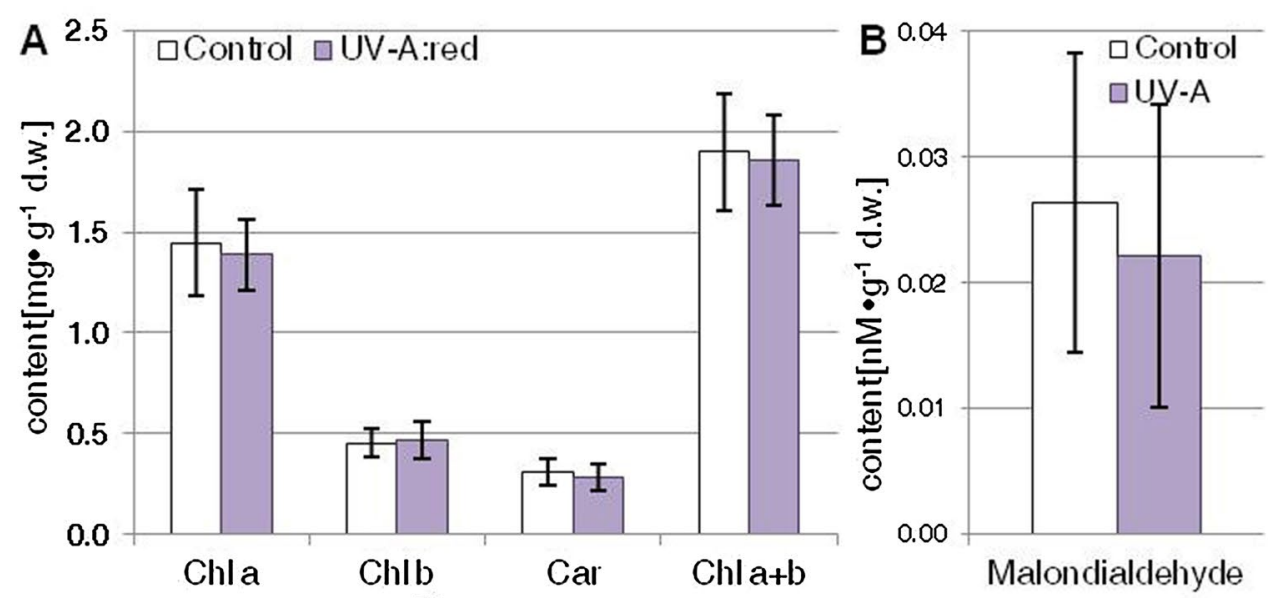

C

Pigments

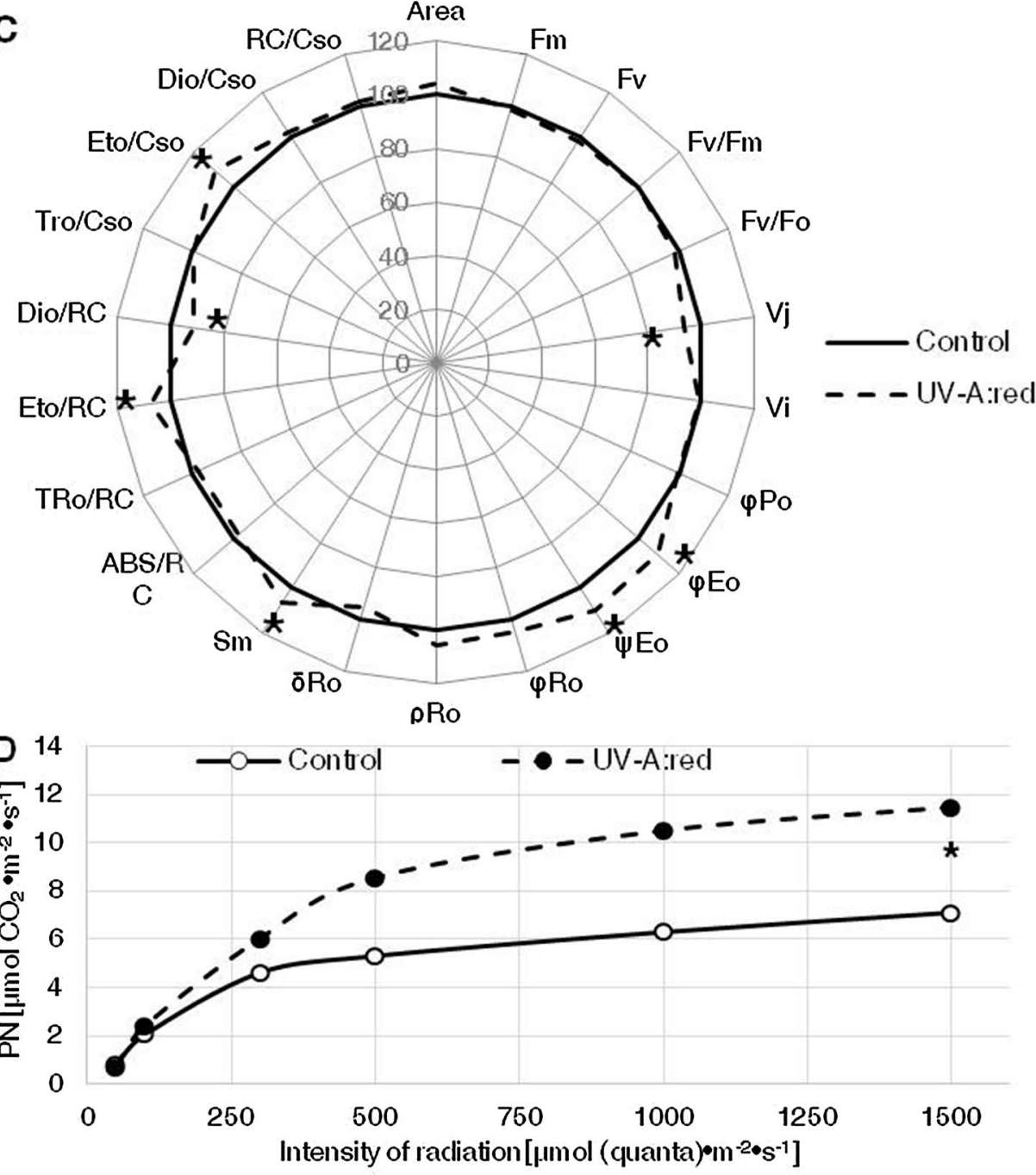


Table 2 Net photosynthesis $\left[\mathrm{P}_{\mathrm{N}}\left(\mu \mathrm{mol} \quad \mathrm{CO}_{2} \mathrm{~m}^{-2} \cdot \mathrm{s}^{-1}\right)\right]$, stomatal conductance [Gs $\left.\left(\mathrm{mmol} \mathrm{H} \mathrm{H}_{2} \mathrm{O} \mathrm{m}{ }^{-2} \cdot \mathrm{s}^{-1}\right)\right]$ and rate of transpiration [E $\left(\mathrm{mmol} \mathrm{H}_{2} \mathrm{O} \mathrm{m}^{-2} \cdot \mathrm{s}^{-1}\right)$ ] in 14-day-old grass pea seedlings after $48 \mathrm{~h}$ of UV-A:red radiation treatment

\begin{tabular}{lll}
\hline Parameter & Control & UV-A:red \\
\hline $\mathrm{P}_{\mathrm{N}}$ & $2.058 \pm 0.008$ & $2.400^{*} \pm 0.041$ \\
$\mathrm{Gs}$ & $0.062 \pm 0.013$ & $0.082 \pm 0.024$ \\
$\mathrm{E}$ & $0.865 \pm 0.136$ & $1.123 \pm 0.271$ \\
\hline
\end{tabular}

*Significant difference between treatments according to Duncan's test at $p<0.05$

Author contribution statement Krzysztof Tokarz designed and performed experiments, discussed the results and wrote the paper; Barbara Piwowarczyk analyzed data and wrote the paper; Anna Wysocka and Wojciech Makowski gave technical support and performed experiments; Tomasz Wójtowicz discussed the results and wrote the paper; Elżbieta Golemiec gave scientific and technical support; All authors proofread manuscript.

Acknowledgements This Research was financed by the Ministry of Science and Higher Education of the Republic of Poland (DS 3500).

Open Access This article is distributed under the terms of the Creative Commons Attribution 4.0 International License (http://creativeco mmons.org/licenses/by/4.0/), which permits unrestricted use, distribution, and reproduction in any medium, provided you give appropriate credit to the original author(s) and the source, provide a link to the Creative Commons license, and indicate if changes were made.

\section{References}

Barnes PW, Kersting AR, Flint SD, Beyschlag W, Ryel RJ (2013) Adjustments in epidermal UV-transmittance of leaves in sunshade transitions. Physiol Plant 149:200-213

Dhindsa RS, Plumb-Dhindsa P, Thorpe TA (1981) Leaf senescence: correlated with increased levels of membrane permeability and lipid peroxidation, and decreased levels of superoxide dismutase and catalase. J Exp Bot 32(1):93-101

Giuliano G (2014) Plant carotenoids: genomics meets multi-gene engineering. Curr Opin Plant Biol 19:111-117

Grela ER, Rybiński W, Klebaniuk R, Matras J (2010) Morphological characteristics of some accessions of grass pea (Lathyrus sativus L.) grown in Europe and nutritional traits of their seeds. Genet Resour Crop Ev 57(5):693-701

Hollósy F (2002) Effects of ultraviolet radiation on plant cells. Micron 33(2):179-197

Jiang HX, Chen LS, Zheng JG, Han S, Tang N, Smith BR (2008) Aluminum-induced effects on photosystem II photochemistry in Citrus leaves assessed by the chlorophyll a fluorescence transient. Tree Physiol 28(12):1863-1871

Joshi PN, Ramaswamy NK, Iyer RK, Nair JS, Pradhan MK, Gartia S, Biswal B, Biswal UC (2007) Partial protection of photosynthetic apparatus from UV-B-induced damage by UV-A radiation. Environ Exp Bot 59(2):166-172
Kalaji HM, Govindjee Bosa K, Kościelniak J, Żuk-Gołaszewska K (2011) Effects of salt stress on photosystem II efficiency and $\mathrm{CO}_{2}$ assimilation of two Syrian barley landraces. Environ Exp Bot 73:64-72

Kale R, Hebert AE, Frankel LK, Sallans L, Bricker TM, Pospíšil P (2017) Amino acid oxidation of the D1 and D2 proteins by oxygen radicals during photoinhibition of Photosystem II. Proc Natl Acad Sci USA 114(11):2988-2993

Kataria S, Jajoo A, Guruprasad KN (2014) Impact of increasing ultraviolet-B (UV-B) radiation on photosynthetic processes. J Photochem Photobiol, B 137:55-66

Kreslavski VD, Lyubimov VY, Shirshikova GN, Shmarev AN, Kosobryukhov AA, Schmitt FJ, Friedrich T, Allakhverdiev SI (2013) Preillumination of lettuce seedlings with red light enhances the resistance of photosynthetic apparatus to UV-A. J Photochem Photobiol, B 122:1-6

Kreslavski VD, Schmitt FJ, Keuer C, Friedrich T, Shirshikova GN, Zharmukhamedov SK, Kosobryukhov AA, Allakhverdiev SI (2016) Response of the photosynthetic apparatus to UV-A and red light in the phytochrome B-deficient Arabidopsis thaliana L. hy3 mutant. Photosynthetica 54(3):321-330

Li L, Aro EM, Millar AH (2018) Mechanisms of photodamage and protein turnover in photoinhibition. Trends Plant Sci 23(8):667-676

Lichtenthaler HK (1987) Chlorophylls and carotenoids: pigments of photosynthetic biomembranes. Method Enzymol 148:350-382

McKenzie R, Smale D, Kotkamp M (2004) Relationship between UVB and erythemally weighted radiation. Photochem Photobiol Sci 3(3):252-256

Moan J (2001) Visible light and UV radiation. In: Brune A, Hellborg R, Persson BRR, Pääkkönen R (eds) Radiation at Home Outdoors and in the Workplace. Scandinavian Science Publisher, Oslo, pp $69-85$

Piwowarczyk B, Kamińska I, Rybiński W (2014) Influence of PEG generated osmotic stress on shoot regeneration and some biochemical parameters in Lathyrus culture. Czech J Genet Plant Breed 50(2):77-83

Piwowarczyk B, Tokarz K, Kamińska I (2016) Responses of grass pea seedlings to salinity stress in in vitro culture conditions. Plant Cell Tiss Org 124(2):227-240

Piwowarczyk B, Tokarz K, Makowski W, Łukasiewicz A (2017) Different acclimatization mechanisms of two grass pea cultivars to osmotic stress in in vitro culture. Acta Physiol Plant 39:96

Piwowarczyk B, Tokarz K, Muszyńska E, Makowski W, Jędrzejczyk R, Gajewski Z, Hanus-Fajerska E (2018) The acclimatization strategies of kidney vetch (Anthyllis vulneraria $\mathrm{L}$ ) to $\mathrm{Pb}$ toxicity. Environ Sci Pollut Res 25(20):19739-19752

Salama HMH, Al-Watban AA, Al-Fughom AT (2011) Effect of ultraviolet radiation on chlorophyll, carotenoid, protein and proline contents of some annual desert plants. Saudi J Biol Sci 18(1):79-86

Silvestre S, de Sousa Araújo S, Vaz Patto MC, Marques da Silva J (2014) Performance index: an expeditious tool to screen for improved drought resistance in the Lathyrus genus. J Integr Plant Biol 56(7):610-621

Singh R, Tripathi RD, Dwivedi S, Kumar A, Trivedi PK, Chakrabarty D (2010) Lead bioaccumulation potential of an aquatic macrophyte Najas indica are related to antioxidant system. Bioresour Technol 101(9):3025-3032

Štroch M, Materová Z, Vrábl D, Karlický V, Šigut L, Nezval J, Špunda V (2015) Protective effect of UV-A radiation during acclimation of the photosynthetic apparatus to UV-B treatment. Plant Physiol Biochem 96:90-96

Tokarz K, Makowski W, Banasiuk R, Krolicka A, Piwowarczyk B (2018) Response of Dionaea muscipula J. Ellis to light stress in in vitro: physiological study. Plant Cell Tiss Organ Cult 134(1):65-77 
Turcsányi E, Vass I (2000) Inhibition of photosynthetic electron transport by UV-A radiation targets the photosystem II complex. Photochem Photobiol 72:513-520

Tyystjärvi E (2008) Photoinhibition of photosystem II and photodamage of the oxygen evolving manganese cluster. Coord Chem Rev 252:361-376

Tyystjarvi E, Vass I (2004) Light emission as a probe of charge separation and recombination in the photosynthetic apparatus: relation of prompt fluorescence to delayed light emission and thermoluminescence. In: Papageorgiou GC, Govindjee (eds) Chlorophyll a fluorescence, Advances in photosynthesis and respiration, vol 19. Springer, Dordrecht, pp 363-388

Urban L, Charles F, de Miranda MRA, Aarrouf J (2016) Understanding the physiological effects of UV-C light and exploiting its agronomic potential before and after harvest. Plant Physiol Biochem 105:1-11

Vass I, Szilárd A, Sicora C (2005) 43 Adverse effects of UV-B light on the structure and function of the photosynthetic apparatus. In: Handbook of photosynthesis, pp. 43-63

Vaz Patto MC, Skiba B, Pang ECK, Ochatt SJ, Lambein F, Rubiales D (2006) Lathyrus improvement for resistance against biotic and abiotic stresses: from classical breeding to marker assisted selection. Euphytica 147:133-147
Verdaguer D, Jansen MA, Llorens L, Morales LO, Neugart S (2017) UV-A radiation effects on higher plants: exploring the known unknown. Plant Sci 255:72-81

Wang H, Gu M, Cui J, Shi K, Zhou Y, Yu J (2009) Effects of light quality on $\mathrm{CO}_{2}$ assimilation, chlorophyll-fluorescence quenching, expression of Calvin cycle genes and carbohydrate accumulation in Cucumis sativus. J Photochem Photobiol, B 96(1):30-37

Wellburn AR (1994) The spectral determination of chlorophylls a and $\mathrm{b}$, as well as total carotenoids, using various solvents with spectrophotometers of different resolution. J Plant Physiol 144:307-313

Wuytack EY, Phuong LDT, Aertsen A, Reyns KMF, Marquenie D, De Ketelaere B, Masschalck B, Van Opstal I, Diels AMJ, Michiels CW (2003) Comparison of sublethal injury induced in Salmonella enterica serovar Typhimurium by heat and by different nonthermal treatments. J Food Prot 66:31-37

Zsiros O, Allakhverdiev SI, Higashi S, Watanabe M, Nishiyama Y, Murata N (2006) Very strong UV-A light temporally separates the photoinhibition of photosystem II into light-induced inactivation and repair. Biochem Biophys Acta, Bioenerg 1757(2):123-129

Publisher's Note Springer Nature remains neutral with regard to jurisdictional claims in published maps and institutional affiliations. 